\title{
Explorando a relação mente-cérebro: reflexões e diretrizes
}

\section{Exploring mind-brain relationship: reflections and guidelines}

\author{
AleXander Moreira-Almeida ${ }^{1}$ \\ I Núcleo de Pesquisas em Espiritualidade e Saúde (Nupes), Faculdade de Medicina da Universidade Federal de Juiz de Fora (UFJF), Juiz de Fora, MG, Brasil.
}

Este artigo é uma versão traduzida e adaptada do Preface e Conclusion da obra: Moreira-Almeida A, Santos FS, editors. Exploring frontiers of the mind-brain relationship. New York: Springer; 2012.

Recebido: 12/4/2013 - Aceito: 15/4/2013

\begin{abstract}
Resumo
Contexto: O avanço no entendimento da mente e sua relação com o cérebro tem sido prejudicado por equívocos filosóficos e metodológicos. Objetivo: Discutir brevemente e propor diretrizes epistemológicas e metodológicas para uma frutífera investigação da relação mente-cérebro. Resultados: A relação mente-corpo ainda é um problema em aberto, não havendo evidências conclusivas de que a mente seja apenas um produto da atividade cerebral. Na exploração da mente, deve-se evitar a aceitação ou rejeição prematura de teorias, buscando não apenas evidências confirmatórias, mas também as falseadoras de uma teoria. Deve-se ampliar e diversificar a base empírica, buscando especialmente experiências humanas não usuais, tais como as chamadas experiências anômalas ou espirituais. A observação de fenômenos anômalos que não se encaixavam nos paradigmas estabelecidos foi essencial em revoluções científicas prévias. Tanto dados quantitativos quanto qualitativos devem ser valorizados. Para explicar a mente e suas múltiplas manifestações, é essencial haver abertura e rigor para criar, desenvolver e testar alternativas teóricas. Candidatos a paradigma de base tanto materialista quanto não materialista devem ter oportunidade de ser apresentados, aprimorados e testados. Conclusão: A ampliação e a diversificação da base empírica aliada a uma postura epistemológica e metodológica mais adequada são essenciais para o avanço da compreensão da relação mente-cérebro.
\end{abstract}

Moreira-Almeida A / Rev Psiq Clín. 2013;40(3):105-9

Palavras-chave: Relações mente-corpo, psicofisiologia, epistemologia, consciência, metodologia.

\begin{abstract}
Background: Philosophical and methodological misconceptions have hampered advances in the understanding of mind and its relationship with the brain. Objective: To discuss and propose epistemological and methodological guidelines for a fruitful investigation of mind-brain relationship. Results: Mind-brain problem is still an open quest, there is no conclusive evidence that mind is just a product of brain activity. In exploring mind one should avoid premature acceptance or rejection of theories, searching not only for confirmatory evidence, but also for the falsifying ones. It is needed enlarging and diversifying the empirical basis, looking especially for unusual human experiences such as those called anomalous and spiritual. Observation of anomalous phenomena, that did not fit established paradigms, was essential in early scientific revolutions. Both qualitative and quantitative data must be valued. In order to explain mind and its myriad of manifestations, it is essential to have openness and rigor to create, develop and test theoretical alternatives. Both, materialist and non-materialist paradigm candidates deserve the same opportunity of being presented, improved and tested. Discussion: The broadening and diversification of the empirical base allied to a more fruitful epistemological and methodological stance are essential for the advancing of our understanding of mind-brain relationship.
\end{abstract}

Moreira-Almeida A / Rev Psiq Clín. 2013;40(3):105-9

Keywords: Mind-body relations, psychophysiology, epistemology, consciousness, methodology.

\section{Introdução}

A compreensão da mente e da consciência é um dos empreendimentos mais estimulantes e desafiadores na busca humana pela compreensão de nós mesmos e do universo como um todo. A questão essencial é: qual a natureza da mente e sua relação com o cérebro? O que nos torna humanos e nos provê qualidades e habilidades que nos tornam quem somos? Qual é a fonte da nossa experiência do "eu"? A despeito de sua importância, essas questões foram frequentemente negligenciadas pela filosofia e ciência durante boa parte do século XX. Contudo, nas últimas duas décadas, tem havido um estimulante renascimento do interesse nesse tema no meio acadêmico.

Descobertas em neurociências e neurotecnologia têm proporcionado uma janela única através da qual podemos observar o intrincado trabalho do cérebro humano. Embora as tecnologias tenham se desenvolvido muito, elas também têm mostrado as limitações fundamentais que ainda persistem na nossa compreensão da mente humana. Como colocado por um dos principais filósofos da mente da atualidade, David Chalmers ${ }^{1}$, a despeito dos extraordinários avanços da neurociência, a busca da explicação da experiência consciente se constitui em um dos "mais desconcertantes problemas na ciência da mente" (p. 200).

Lamentavelmente, diversos problemas e mal-entendidos teóricos, filosóficos e metodológicos têm prejudicado um maior avanço no entendimento da mente e sua relação com o cérebro. Este artigo tem como objetivo discutir brevemente e chamar a atenção dos interessados no estudo da mente e da neurociência para alguns desses aspectos mais importantes, com o intuito de facilitar o progresso no entendimento da relação mente-cérebro.

\section{Mente como produto do cérebro: um fato científico?}

Um obstáculo ao avanço em relação aos problemas da relação mente-cérebro é o fato de que muitas pessoas, mesmo no mundo acadêmico, pensam que essas questões já foram resolvidas. Elas frequentemente acreditam que o cérebro humano é a resposta, que a mente não existe, ou que é apenas um produto (para alguns, um epifenômeno, um subproduto ineficiente) da química e da atividade 
elétrica cerebral. Muitos também veem o cérebro como uma entidade que pode ver, ouvir, pensar, sentir e tomar decisões. Contudo, essas parecem ser conclusões precipitadas. Como colocado por Sir John Eccles, neurocientista ganhador do prêmio Nobel, em seu livro em coautoria com o filósofo da ciência Karl Popper:

"Há uma tendência geral a superestimar o conhecimento científico do cérebro, o que, infelizmente, também é feito por muitos cientistas e divulgadores da ciência. Por exemplo, nos é dito que o cérebro 'vê' linhas, ângulos (...) e que assim nós, em breve, seremos capazes de explicar como uma imagem completa é 'vista' (...). Mas esta afirmação é enganosa. Tudo o que efetivamente se sabe acontecer no cérebro é que neurônios do córtex visual disparam impulsos em resposta a algum estímulo visual especifico". (p. 225)

Uma queixa similar foi feita por outra dupla, formada por um filósofo e um neurocientista, que considera que "a atribuição de atributos psicológicos - em particular cognitivos e reflexivos - ao cérebro é (...) uma fonte de (...) confusão. (...) as grandes descobertas das neurociências não requerem esta forma equivocada de explicação"3 (p. 3-4, grifo no original).

Embora o materialismo reducionista seja uma hipótese que valha a pena ser investigada, não é um "fato científico", como muitos acreditam. O materialismo não é uma consequência necessária e lógica da pesquisa científica. Nesse sentido, vários reducionistas aceitam que ele ainda não é "um fato científico provado", mas que o será em breve. Essa crença de que, "em algum ponto não especificado no futuro" (p. 205), será cientificamente demonstrado como o cérebro gera a mente é o que Popper e Eccles chamaram de materialismo promissório ${ }^{2}$ Saulo Araujo, em uma minuciosa investigação histórica ${ }^{4}$, concluiu que o materialismo promissório tem sido uma estratégia retórica utilizada há pelo menos 300 anos, mas a profecia de uma demonstração e uma explicação estritamente materialista da mente sempre prometidas para um futuro breve até hoje não se concretizou.

\section{Reflexões e diretrizes epistemológicas e metodológicas}

\section{Evitar a aceitação prematura de teorias}

O reducionismo é uma estratégia de trabalho legítima em relação ao problema mente-cérebro, contudo, se ela é apressadamente tomada como a resposta definitiva e final, isso pode levar a um fechamento prematuro e dogmático dessa busca, que é um dos mais importantes desafios ao conhecimento humano. Esse fechamento é uma postura epistemológica perigosa, já que o fato concreto é que ainda estamos longe de efetivamente compreender e explicar a mente. Usando a terminologia do filósofo da ciência Thomas Kuhn ${ }^{5}$, poderíamos dizer que estamos em uma fase pré-paradigmática em relação ao problema mente-cérebro. Um período pré-paradigmático é quando não há a aceitação consensual pela comunidade científica de um paradigma específico (uma estrutura de teorias-chave, instrumentos, valores e pressupostos metafísicos para uma dada disciplina acadêmica) ${ }^{6}$. Existem vários candidatos a paradigma para o estudo da consciência, mas nenhum efetivamente chegou a esse ponto ainda, caracterizando-se o campo como uma ciência imatura.

Uma das consequências adversas da aceitação prematura de uma teoria é que encontrar exemplos confirmatórios de quase qualquer teoria é uma tarefa fácil7. Muitos dados são frequentemente apresentados para apoiar a ideia de que a mente já foi completamente explicada como um produto da atividade cerebral. Isso frequentemente inclui exemplos da concomitância psicofisiológica e a demonstração de que lesões cerebrais ou alterações neurofisiológicas são frequentemente seguidas por alguma alteração na mente. Contudo, como William James demonstrou há mais de um século ${ }^{8}$, esses dados também podem ser acomodados por uma teoria da transmissão em que o cérebro atua como um filtro, tendo uma "função transmissiva ou permissiva" (p. 291), agindo como "um órgão para limitar e determinar a uma certa forma a consciência produzida em outro lugar (p. 294). Também, conforme colocado por Chalmers ${ }^{1}$, estudar os correlatos neurais da consciência não é o mesmo que explicar a consciência ou como e por que esses processos poderiam dar origem à experiência consciente. Há um "abismo explicativo (explanatory gap) entre as funções (cerebrais) e a experiência, e precisamos de uma ponte explicativa para atravessá-la" (p. 203). De acordo com James ${ }^{8}$, a teoria da transmissão teria uma vantagem explicativa sobre a teoria da produção (em que o cérebro produz a mente). Além de explicar as predições da teoria da produção (especificamente a concomitância de mudanças no cérebro e na consciência, isto é, os correlatos cerebrais dos fenômenos mentais), a teoria da transmissão:

\begin{abstract}
"também toca uma ampla classe de experiências que são dificilmente explicadas pela teoria da produção. Refiro-me a estes fenômenos obscuros e excepcionais relatados em todos os tempos ao longo da história humana, (...) premoniçães, aparições no período da morte, visões ou impressões clarividentes e ampla gama de capacidades mediúnicas (...). Todas estas experiências, bastante paradoxais e sem sentido na teoria da produção, se encaixam muito naturalmente na outra teoria. Precisamos apenas supor a continuidade da nossa consciência". (p. 298-299)8
\end{abstract}

\section{Buscar evidências que refutem a teoria}

De acordo com o filósofo da ciência Karl Popper, para verdadeiramente testar uma teoria, deveríamos estar comprometidos em buscar evidências que poderiam potencialmente falsear aquela teoria. Uma boa teoria científica resiste a tentativas vigorosas de encontrar evidências contrárias. Contudo, Kuhn mostrou que cientistas frequentemente não são capazes de reconhecer fenômenos não permitidos pelos paradigmas aos quais estão comprometidos:

\begin{abstract}
"Será por acidente, por exemplo, que os astrônomos ocidentais só começaram a ver mudanças nos céus, previamente imutáveis, durante o meio século após o novo paradigma de Copérnico ter sido proposto? Os chineses, cujas crenças cosmológicas não proibiam mudanças celestes, tinham registrado a aparição de muitas novas estrelas no céu em datas muito anteriores". (p. 116)
\end{abstract}

O reconhecimento de que estamos em uma fase pré-paradigmática na exploração do problema mente-cérebro nos capacitaria a empreender investigação mais frutífera. Vale a pena lembrar que as habilidades científicas necessárias para trabalhar em uma fase pré- paradigmática são diferentes daquelas requeridas durante uma fase paradigmática, um período chamado por Kuhn de ciência normal. Um trabalho frutífero em períodos pré-paradigmáticos ou revolucionários requer abordagem mais mente aberta e comprometimento não tão intenso com qualquer um dos candidatos a paradigma. Também se requer que se alargue tanto quanto possível a diversidade da base empírica e se evite uma rejeição apressada de hipóteses9.

\section{Ampliar e diversificar a base empírica}

Uma boa teoria científica precisa ser capaz de explicar um amplo e diversificado leque de fenômenos ${ }^{10}$. Uma teoria baseada em uma variedade limitada de fenômenos tem base muito frágil. A mera repetição de alguns tipos de achados adiciona pouca força e validade a uma dada teoria. Então, a busca deliberada de novos tipos de observações empíricas para testar certo paradigma é de grande valor, porque ela pode oferecer novas e valiosas confirmações ou, ao contrário, pode levar à sua rejeição.

No decorrer da história, revoluções científicas frequentemente ocorreram quando cientistas brilhantes levaram em conta uma ampla variedade de fenômenos previamente desconhecidos ou desprezados. Galileu, com seu telescópio, e Charles Darwin, durante sua viagem de cinco anos no Beagle, reuniram uma enorme massa de evidências empíricas que não estavam disponíveis para a maioria dos cientistas da época. A viagem e o telescópio permitiram que Darwin e Galileu lidassem com um enorme alargamento da base empírica, uma base que não podia mais ser explicada pelos paradigmas astronômicos e biológicos então predominantes. O final dessas histórias é bem 
conhecido por todos nós. O mesmo aconteceu com a física clássica, que, há mais de um século, parecia ser capaz de explicar toda a natureza. Tal certeza fez com que o eminente físico Lord Kelvin afirmasse, em 1900, poucos anos antes de Einstein desenvolver a teoria da relatividade: "não há mais nada de novo a ser descoberto pela física agora, tudo o que resta são medições mais e mais precisas". De fato, a física clássica é muito eficiente para explicar a maioria dos fenômenos físicos que ocorrem em nossas vidas diárias. Contudo, quando começaram os estudos das partículas microscópicas e velocidades extremas, sua limitação se tornou evidente, dando origem à revolução científica da física moderna ${ }^{11}$.

A ciência e a filosofia da mente precisam alargar seu tímido escopo e lidar com um leque muito mais amplo de fenômenos se elas desejam de fato fazer uma contribuição verdadeiramente significante para a compreensão da mente e sua relação com o cérebro. $\mathrm{Na}$ exploração do problema mente-cérebro, é essencial levar em consideração a ampla gama de experiências humanas, não importando quão estranhas elas possam parecer à primeira vista. Especificamente, experiências frequentemente chamadas "anômalas" e/ou "espirituais" constituem um tipo de dado empírico que tem sido negligenciado no último século, mas com alto potencial de ter grande valor heurístico ${ }^{12-16}$. De modo a não repetir os erros descritos anteriormente, para avançar o nosso entendimento, precisamos prestar especial atenção exatamente aos fenômenos mais extremos e desafiadores. Nesse tipo de exploração, é necessário que dados empíricos consistentes tenham supremacia epistemológica sobre hipóteses teóricas estabelecidas ou de preferência do pesquisador", uma abordagem em sintonia com que foi chamado por William James de "empirismo radical"17.

Como em revoluções científicas anteriores em outras áreas da ciência, pensamos que esse alargamento da base empírica pode colaborar de modo decisivo para fazer avançar esse debate, que tem estado estagnado por longo tempo. Por serem vivências da mente humana muito frequentes em todas as culturas ao longo da história, as chamadas "experiências espirituais" precisam ser levadas em conta por qualquer paradigma que pretenda explicar a experiência humana ou então ele será, no mínimo, incompleto. Experiências de transes e possessões já despertaram o interesse de muitos pesquisadores conceituados, gerando investigações fundamentais ao desenvolvimento de conceitos como inconsciente, mente subliminal, dissociação e histeria ${ }^{18-20}$.

Talvez por estarem no centro de crenças e tradições espirituais, essas experiências humanas tão frequentes têm sido negligenciadas por acadêmicos que se recusam a investigá-las seriamente como dados empíricos que podem lançar luz na exploração da natureza humana. Uma possível explicação desse descaso é a confusão entre ciência e as posições metafísicas/filosóficas do cientificismo e do materialismo. Como John Haught discutiu, embora haja uma crença disseminada de que ciência (um método de exploração) seja inseparável da ideologia materialista (uma proposta metafísica, uma visão de mundo), "não está escrito em nenhum lugar que o restante de nós que aprecia ciência tem que acreditar nisto (naturalismo materialista). Na realidade, a maioria dos grandes fundadores da ciência moderna não acreditava. (...) Aquela crença não é uma afirmação científica, mas uma profissão de fé" (p. 367)21. Dado o equivocado amalgamamento de ciência com materialismo, é compreensível que a maioria das discussões acadêmicas evite a investigação de experiências que possam sugerir uma realidade transcendente ou não material, ou, ao menos, levar em consideração esses fenômenos como experiências humanas que merecem ser estudadas a fundo ${ }^{22,23}$. Na realidade, é um equívoco utilizar a visão de mundo materialista como uma limitação ou fronteira para a empreitada científica. Hefner ${ }^{24,25}$ e Reich ${ }^{23}$ argumentam, de modo convincente, sobre o alargamento da base empírica para o estudo científico dos aspectos espirituais da experiência humana, mesmo (ou principalmente) se os dados observacionais não se encaixem nos princípios teóricos (filosóficos) predominantes. Vale ressaltar que já há atualmente um considerável conjunto de evidências sobre experiências espirituais produzidas por rigorosas investigações científicas recentes ${ }^{11,12}$.

\section{Valorizar dados quantitativos e qualitativos}

Outro tipo de preconceito epistemológico ingênuo se relaciona à rejeição de dados qualitativos e à ênfase exagerada em dados quantitativos e análises estatísticas. Frequentemente se esquece de que um dos mais importantes paradigmas científicos contemporâneos, a evolução por seleção natural, emergiu de estudos qualitativos realizados por Charles Darwin ${ }^{26}$. De acordo com o filósofo da ciência Alan Chalmers, pessoas defendendo a ideia de que "se você não pode medir, seu conhecimento é pobre e insatisfatório" não percebem que "o método que eles se esforçam por seguir não é apenas necessariamente estéril e infrutífero, mas também que não é o método ao qual o sucesso da física deve ser atribuído" (p. xiv) ${ }^{27}$.

\section{Abertura para alternativas teóricas}

É também importante não rejeitar uma hipótese explicativa porque ela não está "na moda" ou porque ela tem sido associada à superstição. A formulação da gravidade por Isaac Newton enfrentou forte oposição, porque ele não era capaz (e nós também ainda não somos capazes) de explicar como um objeto pode influenciar outro objeto a distância, sem nenhum contato material. Isso foi um problema ainda mais importante considerando-se que na época dois paradigmas predominantes - mecanicismo e corpuscularismo - afirmavam que as diferentes propriedades da matéria deveriam ser totalmente explicadas pela interação mecânica de corpúsculos ${ }^{28}$. Assim como Newton, Semmelweis e John Snow enfrentaram forte resistência e acusações de superstição e pensamento anticientífico por cientistas de sua época, quando propuseram a teoria dos germes e do contágio. Naquele período, essas ideias eram populares entre pessoas supersticiosas e pouco instruídas, enquanto pessoas bem educadas habitualmente "sabiam" que a teoria dos miasmas era a verdade $29-31$.

Na busca por um paradigma para compreender a consciência, é necessário que ele explique tanto quanto possível o amplo leque das experiências humanas. É essencial manter tanto o rigor científico quanto a humildade intelectual. Como afirmado por Popper: "na busca pela verdade, pode ser nosso melhor plano começar por criticar nossas crenças mais queridas" (p. 6)7.

Infelizmente, tal postura receptiva e aberta não está sempre presente na história da ciência. De acordo com Thomas Kuhn, revoluções científicas não triunfam, porque o novo paradigma foi capaz de converter todos os céticos e líderes da oposição:

"A mudança de adesão de um paradigma para outro é uma experiência de conversão que não pode ser forçada. A resistência de toda uma vida, particularmente daqueles cujas carreiras produtivas comprometeu-os a uma tradição mais antiga de ciência normal, é (...) um indicador da natureza da pesquisa científica em si. A fonte de resistência é a confiança de que o paradigma antigo acabará resolvendo todos os seus problemas (...)

(...) [uma] geração é algumas vezes necessária para realizar a mudança (...). Embora alguns cientistas, particularmente os mais antigos e mais experientes, possam resistir indefinidamente, a maioria deles pode ser alcançada de uma forma ou de outra. Conversões ocorrerão aos poucos até que, após a morte dos últimos opositores, toda a comunidade voltará a praticar ciência sob um único, mas agora novo, paradigma". (p. 151-152)5

$\mathrm{Na}$ busca por um paradigma para explicar a mente e sua relação com o cérebro, torna-se fundamental evitar dogmatismos de quaisquer espécies, estando aberto tanto para aspectos cerebrais como não cerebrais da mente. Como recentemente colocado por David Chalmers ${ }^{32}$, várias limitações importantes das perspectivas materialistas têm sido expostas e as principais objeções a perspectivas não materialistas têm sido superadas, então perspectivas não materialistas deveriam agora receber mais consideração. Ele sugeriu que os dois melhores candidatos para uma teoria científica da mente são o dualismo interacionista e o panprotopsiquismo. Ele afirmou que, contrário à sua inclinação inicial, ele se tornou um tipo de dualista por causa de sua atitude científica de "aceitar (e não desprezar) os 
dados" (p. 4) ${ }^{33}$. Vale refletir sobre suas conclusões a respeito do lugar da consciência na natureza:

"É frequentemente admitido que mesmo sendo difícil ver como o materialismo pode ser verdadeiro, o materialismo tem que ser verdadeiro, posto que as alternativas são inaceitáveis. Do meu ponto de vista, existem em jogo pelo menos três alternativas ao materialismo aceitáveis prima facie (dualismo interacionista, epifenomenalismo e panprotopsiquismo), cada um deles é compatível com uma visão de mundo naturalista (mesmo se não materialista), e nenhum deles tem problemas fatais. Assim, dados os claros argumentos contra o materialismo, parece-me que deveríamos ao menos assumir, como uma conjectura, a conclusão de que uma destas visões está correta. Naturalmente, todas estas visões (...) precisam ser desenvolvidas em muito mais detalhes e examinadas à luz de todos os desenvolvimentos filosóficos e científicos relevantes a fim de serem avaliadas de modo abrangente. Mas como as coisas se mostram, eu penso que nós temos boas razões para supor que a consciência tem um lugar fundamental na natureza". (p. 41-42) $)^{32}$

\section{Aprimoramento e busca de evidências para um candidato a paradigma}

Atualmente é bem reconhecido em filosofia da ciência que não há prova definitiva ou experimento crucial para confirmar uma dada teoria. O desenvolvimento científico raramente é feito de passos claros e bem definidos. A empreitada científica é muito mais incerta e complexa do que gostaríamos. Como afirmado pelo filósofo da ciência Imre Lakatos: "Não existe algo como um experimento crucial, ao menos não no sentido de experimentos que podem derrubar instantaneamente um programa de pesquisa" (p. 173) ${ }^{34}$.

Qualquer teoria científica passa por um período inicial de incerteza, incompletude e suspeição, contudo, se a teoria e seus proponentes são bons o suficiente, essas barreiras são vencidas ${ }^{34}$. Um bom exemplo é a história da evolução pela seleção natural, embora ela seja atualmente um paradigma bem estabelecido na biologia, esse não foi sempre o caso. Muitas evidências favoráveis e desenvolvimentos teóricos vieram apenas décadas mais tarde, na primeira metade do século XX, por meio da integração da genética com a evolução darwiniana, no que é conhecido como neodarwinismo ou "síntese moderna" 35 .

O próprio Charles Darwin admitia que não era possível apresentar, em sua época, uma prova direta e definitiva da seleção natural. Ele dizia àqueles que não se convenceram de sua teoria:

"Não estou de modo algum surpreendido que você não aceite a seleção natural: é muito difícil uma prova ou evidência direta neste tema. Ele será aceito somente por aqueles que pensam que ele conecta e explica parcialmente vários grandes grupos de fatos: do mesmo modo que os ópticos admitem a teoria ondulatória da luz, embora ninguém possa provar a existência do éter ou suas ondulações". ${ }^{36}$

A principal vantagem da evolução por seleção natural sobre teorias concorrentes era o seu poder explicativo, que conectava e dava sentido a um grande corpo de evidências empíricas que não se encaixavam bem nos paradigmas concorrentes. Como afirmou Darwin:

"De fato, a crença na seleção natural precisa no momento ser baseada inteiramente em considerações gerais: (1) nos fatos da luta pela existência e certos fatos geológicos que as espécies de algum modo se transformam, (2) da analogia da mudança sobre domesticação pela seleção do homem, (3) e principalmente desta visão conectando de modo inteligível uma multidão de fatos". 37

\section{Conclusão}

Dadas as evidências disponíveis e nossa limitada compreensão da mente, perspectivas tanto materialistas como não materialistas da mente merecem ao menos a mesma oportunidade de desenvolvimento. Liberdade intelectual é necessária para desenvolver a aprimorar candidatos a paradigma, sem que sejam suprimidos pelo dogmatismo e intolerância. Além disso, de acordo com Lakatos, o desenvolvimento científico ocorre em um tipo de seleção darwiniana de competição entre candidatos a paradigma onde o mais apto sobrevive:

"Seria equivocado assumir que alguém precisa permanecer em um programa de pesquisa até que ele tenha exaurido todo seu poder heurístico, que não se pode introduzir um programa rival antes que todos concordem que o ponto de degeneração provavelmente já chegou. (...)

A história da ciência tem sido e deve ser uma história de competição de programas de pesquisa: quanto antes a competição começar, melhor para o progresso. 'Pluralismo teórico' é melhor que 'Monismo teórico"'. (p. 155) 34

Exatamente por causa disso, vivemos em uma época estimulante. Se reconhecermos humildemente nosso conhecimento muito limitado sobre a consciência e, ao mesmo tempo, enfrentarmos audaciosamente, rigorosamente e criativamente o problema mente-cérebro, como seres humanos, poderemos marchar para uma compreensão mais profunda da nossa própria natureza. Essa é, indubitavelmente, uma empreitada árdua e desafiadora, contudo é um caminho que definitivamente vale a pena trilhar.

\section{Referências}

1. Chalmers DJ. Facing up to the problem of consciousness. J Conscious Stud. 1995;2(3):200-19.

2. Popper KR, Eccles J. The self and its brain. Berlin: Springer Verlag; 1977.

3. Bennett MR, Hacker PMS. Philosophical foundations of neuroscience. Malden: Blackwell; 2003.

4. Araujo SF. O eterno retorno do materialismo: padrões recorrentes de explicações materialistas dos fenômenos mentais. Rev Psiq Clín. 2013;40(3):114-9.

5. Kuhn TS. The structure of scientific revolutions. Chicago: University of Chicago Press; 1970.

6. Bird A. “Thomas Kuhn”. In: Edward NZ, editor. The Stanford Encyclopedia of Philosophy. [internet]. Fall 2009 Edition. Available from: $<$ http:// plato.stanford.edu/entries/thomas-kuhn/\#3>.

7. Popper KR. Conjectures and refutations - the growth of scientific knowledge. London: Routledge; 1995.

8. James W (1898). Human immortality: two supposed objections to the doctrine. In: Murphy G, Ballou RO, editors. William James on psychical research. New York: Viking Press; 1960. p. 279-308.

9. Chibeni SS, Moreira-Almeida A. Investigando o desconhecido: filosofia da ciência e investigação de fenômenos "anômalos" na psiquiatria. Rev Psiq Clín. 2007;34(Suppl 1):8-15.

10. Hempel CG. The philosophy of natural science. Englewood Cliffs, NJ Prentice-Hall; 1996.

11. Greyson B. Experiências de quase-morte: implicações clínicas. Rev Psiq Clín. 2007;34(Suppl 1):116-25.

12. Moreira-Almeida A, Santos FS. Exploring frontiers of the mind-brain relationship. New York: Springer; 2012.

13. Cardeña E, Lynn SJ, Krippner S. Varieties of anomalous experience: examining the scientific evidence. Washington DC: American Psychological Association; 2000.

14. James W. (1909). The final impressions of a psychical researcher. In: Murphy G, Ballou RO, editors. William James on psychical research. New York: Viking Press; 1960. p. 309-25.

15. Kelly EF, Kelly EW, Crabtree A, Gauld A, Grosso M, Greyson B. Irreducible mind: toward a psychology for the 21st century. Lanham: Rowman \& Littlefield Publishers; 2007.

16. Eysenck HJ, Sargent C. Explaining the unexplained: mysteries of the paranormal. London: Prion; 1993.

17. Sech Junior A, Araújo SF, Moreira-Almeida A. William James and psychical research: toward a radical science of mind. History of Psychiatry. 2013;24:62-78.

18. Almeida AM, Lotufo Neto F. A mediunidade vista por alguns pioneiros da área da saúde mental. Rev Psiq Clín. 2004;31:132-41. 
19. Alvarado CS, Machado FR, Zangari W, Zingrone NL. Perspectivas históricas da influência da mediunidade na construção de ideias psicológicas e psiquiátricas. Rev Psiq Clín. 2007;34(Suppl 1):42-53.

20. Crabtree A. From Mesmer to Freud: magnetic sleep and the roots of psychological healing. New Haven: Yale University Press; 1993.

21. Haught JF. Science and scientism: the importance of a distinction. Zygon: J Relig Sci. 2005;40:363-8.

22. Walach H, Reich KH. Reconnecting science and religion: toward overcoming a taboo. Zygon: J Relig Sci. 2005;40:423-41.

23. Reich KH. What needs to be done in order to bring the science-and-religion dialogue forward? Zygon: J Relig Sci. 2007;42:269-72.

24. Hefner P. Religion and science-two way traffic? Zygon: J Relig Sci. 2006;41:3-6.

25. Hefner P. Science and the big questions. Zygon: J Relig Sci. 2007;42:265-8.

26. Ghiselin MT. The triumph of Darwinian method. Berkeley: University of California Press; 1972.

27. Chalmers AF. What is this thing called science? An assessment of the nature and status of science and its methods. Indianapolis: Hackett; 1978.

28. BlackBurn S. The Oxford dictionary of philosophy. Oxford: Oxford University Press; 2008.

29. Lilienfeld DE. "John Snow: the first hired gun?" Am J Epidemiol. 2000;152(1):4-9.
30. Smith GD. Commentary: Behind the Broad Street pump: etiology, epidemiology and prevention of cholera in mid-19th century Britain. Int J Epidemiol. 2002;31(5):920-32.

31. Vandenbroucke JP. Invited commentary: the testimony of Dr. Snow. Am J Epidemiol. 2000;152(1):10-2.

32. Chalmers DJ. Consciousness and its place in nature. In: Stich SP, Warfield TA, editors. Blackwell Guide to Philosophy of Mind. Malden: Blackwell; 2003.

33. Chalmers DJ. Mind and consciousness: five questions. In: Grim P, editor. Mind and consciousness: five questions. Copenhagen: Automatic Press; 2009.

34. Lakatos I. Falsification and the methodology of scientific research programmes. In: Lakatos I, Musgrave A, editors. Criticism and the growth of knowledge. Cambridge: Cambridge University Press; 1970. p. 91-195.

35. Wade M. Evolutionary Genetics. In: Zalta EN, editor. The Stanford Encyclopedia of Philosophy [internet]. Fall 2008 Edition. Available from: $<$ http://plato.stanford.edu/archives/fall2008/entries/evolutionary-genetics $>$.

36. Darwin C. Darwin Correspondence Project Database. [internet]. Available from: <http://www.darwinproject.ac.uk/entry-3608/< (letter $n^{\circ}$ 3608). Accessed: May 25, 2010.

37. Darwin C. Darwin Correspondence Project Database. [internet]. Available from: <http://www.darwinproject.ac.uk/entry-4176/> (letter $n^{\circ}$ 4176). Accessed: May 25, 2010. 